\title{
Editorial
}

\section{International Archives of Allergy and Immunology: A Commitment to Serving the Community Worldwide}

\author{
Hans-Uwe Simon \\ Institute of Pharmacology, University of Bern, Bern, Switzerland
}

It is a fine tradition that the newly appointed Editorin-Chief of a scientific journal communicates some key thoughts to the journal's readers. The International Archives of Allergy and Immunology (IAAI) has provided an international forum for high-quality, innovative research in the fields of allergy and immunology since 1950. I am indeed delighted to take over the position, beginning January 1, 2018, of Barbara Bohle and Rudolf Valenta, who have served as Co-Editors-in-Chief of IAAI since 2003. Under their leadership, this journal has developed a global character and is known to publish high-quality articles, in terms of both science and its technical presentation. In this role, IAAI provides important services to scientists and clinicians in the fields of allergy and immunology worldwide.

As the new Editor-in-Chief, I want this journal to develop into a leading voice in the allergy and immunology community. We will cover the entire spectrum of allergy and immunology. Specifically, we will publish both basic and clinical original reports, but also review articles which can help readers to always be up to date in the dynamic field of research. In addition, we will publish opinion articles to provide a forum for the discussion of novel ideas and potentially controversial findings.

The quality, international awareness, and impact of a scientific journal are the product of the teamwork provided by the Editor-in-Chief, Associate Editors, Editorial

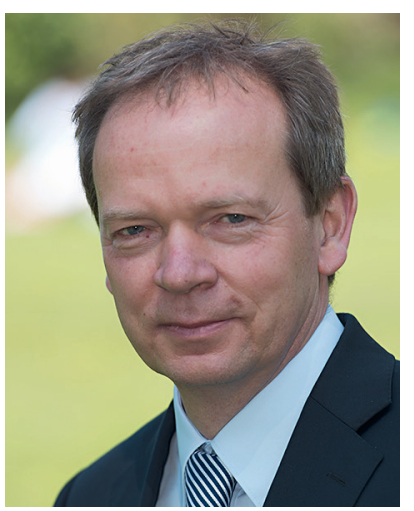

Hans-Uwe Simon, MD (Jena, Germany), PhD (Jerusalem, Israel), Dr hc (Ljubljana, Slovenia), works at the Faculty of Medicine of the University of Bern, Switzerland. He is the Director of the Institute of Pharmacology and currently serves as Dean of the Medical Faculty. He has made significant editorial contributions to the scientific community, being Editor-in-Chief of Allergy (2009-2018) and Cell Death \& Disease (since 2016), with impact factors of 7.4 and 6.0 , respectively. His scientific interest focuses on programmed cell death in inflammatory diseases and cancer, where his contribution has been fundamental.

Board members, publisher, and all authors. I have appointed four Associate Editors, each with different research experience, but all known for their own important scientific contributions to the field. We also have a new Editorial

\section{KARGER}

(c) 2018 S. Karger AG, Basel 
Board, made up of members willing to work hard for our authors and readers. Our goal is to reach an initial decision about a manuscript within 4 weeks after submission.

We are currently a small group of active people and are aware that developing a journal is a dynamic process. Please note that the new Editorial team of IAAI is open and willing to involve additional individuals, either as Board members or Associate Editors. Specifically, young scientists can gain a lot of experience by evaluating the research reports, thus obtaining important insights into the publishing process. Please contact me or any of the Associate Editors if you want to be involved in the challenging task of serving IAAI.
The quality of a journal depends largely on the quality of the research work submitted. We are aware that we need to convince authors to publish their best works in IAAI. We promise a fair and rapid process of evaluation, and you will receive constructive feedback to improve your papers. In this way, we are hoping to convince you that it is always worthwhile to send your work to IAAI, because your manuscript is going to be handled in a helpful, but also most professional manner. We look forward to receiving your manuscripts and working together with you to increase the impact of $I A A I$, thus contributing to the development of the important fields of allergy and immunology. 